\title{
Mapping Palestine: Erasure and Unerasure
}

\author{
Ahmad Barclay
}

Jewish villages were built in the place of Arab villages. You don't even know the names of these Arab villages, and I don't blame you, because these geography books no longer exist ... Nahalal arose in the place of Mahlul, Gvat in the place of Jibta, Sarid in the place of Haneifa, and Kfar-Yehoshua in the place of Tel-Shaman. There is not one single place built in this country that did not have a former Arab population.

Moshe Dayan, Israeli defence minister (quoted in Ha'aretz, 4 April 1969).

Contrary to Dayan's words, the geography books continue to exist. A couple of years ago I discovered that the Israeli national library had made available a series of highly detailed 1940s maps-at 1:20,000 scale-from the British Mandate "Survey of Palestine" through a map viewer on its website. I had known about the existence of such maps, and that copies could be found in various Israeli archives. But, knowing also how difficult it can be for non-Israelis-and even for Palestinian citizens of Israelto gain unfettered access to such maps in the archives themselves, I was somewhat surprised by the fact that an Israeli government institution would make them available in such a way, and under the bold title "Palestine", no less. 
While these maps could be viewed on the library website, they could not easily be downloaded. And, further, they could not be viewed, searched or otherwise navigated as a continuous map of the territory, thus limiting their meaningful value to a typical user. In total, there are 155 unique map sheets in the 1:20,000 series, covering the most populous part of the country, from Beersheba in the south to the northern borders with Lebanon and Syria. Alongside these, the library website hosts less detailed-and less rare-1:100,000 and 1:250,000 maps that together cover the whole country, and various larger-scale maps covering at least twenty major towns and cities in building-by-building detail. Together these are still just a fraction of the survey maps produced under British rule.

\section{The Significance of the Maps}

The significance of these maps will be obvious to anyone familiar with the history of Palestine/Israel. The maps capture, in impressive detail, a snapshot of the country just years-in some cases even just months-before 750,000 Palestinians were ethnically cleansed (Pappe 2006: 1-9) from over 500 towns and villages across the part of Mandate Palestine that in 1948 would come under the rule of the new State of Israel. This series of events is known in Palestinian collective memory as the Nakba (meaning "catastrophe" in Arabic).

The maps do not just plot and name each of these depopulated and destroyed communities; they name literally tens of thousands of landmarks, from mountains, valleys and rivers to orchards, water cisterns and wayside shrines. In fact, they also demarcate and name every rural parcel of land across much of the country. And each and every name is systematically transliterated from Arabic (an official transliteration schema was published in The Palestine Gazette, 2 October 1941). 
Names are important. From the first days of its existence, the State of Israel enlisted "naming committees" to create a new Hebrew map of the new country, systematically renaming every possible landmark, natural and man-made, using the very maps and gazetteers that had been produced under the British as their guide (Benvenisti 2000: 11-54). In its first decades, official Israeli maps changed faster than the facts on the ground. Depopulated Palestinian villages had vanished from new "Survey of Israel" maps by 1951, and were over-printed with the Hebrew word harus (meaning "destroyed") on updates of British maps (Benvenisti 2000: 41). In reality, the many of them would not be destroyed by Israeli authorities for some years (Rapoport 2007), and a handful-including Lifta, Iqrit and Kfar Bir'im-even remain largely intact today.

\section{A Prelude to Erasure}

[T]he roots of the modern survey system of Palestine set up by the military government are to be sought in the Balfour Declaration and its implications regarding land. The system was formally established in July 1920 with only one objective: to survey and map the lands of the country as demanded by the Zionist Organisation, in order to implement legally binding land settlement and registration of tenure rights.

Dov Gavish (2005: xiii).

It is important to note that, although the British maps vividly capture the historical moment before the Nakba, they are not a neutral artefact. Their primary purpose was not to stand testament to the national claims of Palestinians. Rather, they were intended as a blueprint for colonization. As Israeli geographer Dov Gavish describes, by mapping the land in such detail, the British had in fact 
sought to facilitate the Zionist colonization of Palestine. The aim was to formalize the ownership claims over every square metre of the territory in order that lands could be sold or otherwise transferred to Zionist organizations such as the Jewish National Fund or Palestine Jewish Colonization Association. Within the first decade of the Mandate, the British also enacted a raft of ordinances and regulations designed to support this endeavour (Gavish 2005: 95-136). The Zionist imperative to map land ownership in this comprehensive and systematic way stands in stark contrast, of course, to narratives of Palestine as an "empty land" or "a land without a people" prior to its Zionist colonization.

From another perspective, the British maps-as with any mapscome with their own biases and selectivity. For example, every sheet is dotted with scores of water cisterns, which one can reasonably assume was due to a belief in the strategic importance of water resources in the region. Likewise, every ruin of potential biblical significance seems to find its way onto the maps, likely owing to earlier maps by the Palestine Exploration Fund, a British society that had extensively surveyed Palestine for evidence of biblical remains during the 1870 s.

\section{Resurrecting the Maps, Reanimating Palestine}

Salmon emphasised the human aspect of carto-topography. No matter how accurate the map, Salmon wrote, people would never trust it if it were not pleasant and attractive to the eye, for it was impossible not to be affected by its external appearance.

Gavish (2005: 192), describing the writings of F.J. Salmon, director of the Survey of Palestine from 1933 to 1938. 
I couldn't have done anything without the marvelous detailed maps (scale 1:20,000) compiled by the Mandatory authorities and updated just before the 1948 War. I would spread the relevant map on the ground, and suddenly the old landscape arose like an apparition: village houses, mosques, school buildings, paths, stone hedges marking plot boundaries, limekilns, threshing floors, holy tombs, sacred oak trees, springs and cisterns, caves, fruit trees, patches of cultivation. And each plot and every prominent feature had its Arabic name marked on the map, so poetic and so apt ... that my heart ached.

Benvenisti (2000: 8), describing the role of the maps during his efforts to uncover a Palestinian landscape erased by Israeli cartographers.

On discovering these maps and noting that their copyright had expired under UK law, I set about working with Visualizing Palestine (VP) to make them available to as wide an audience as possible. VP is an organization engaged in visual storytelling projects on Palestine and Palestinians using data visualizations, mapping and infographics-and with which I have been working over the past seven years-so it seemed like a fitting home for the project.

It should be noted that, although many digital maps exist reconstructing Palestine before the Nakba-including Salman Abu Sitta's Atlas of Palestine (2010) and Zochrot's iNakba app-we saw a power in making the historic maps themselves available, as they seemed to offer a raw testimony that digital reproductions simply cannot. The quotes of J.F. Salmon and Meron Benvenisti help to capture the aesthetic and even emotive power of these particular maps, while there is also an undeniable sense of "truth" to historical maps, regardless of the original intent in their creation. 
The objective of our project was to build an intuitive Google Maps-style platform that would allow users to navigate, search and download the maps. Realizing this project, eventually named Palestine Open Maps (POM)-palopenmaps.org-involved four stages. Firstly, finding a way to download the maps from the Israeli National Library website. Secondly, piecing together these maps into a continuous digital base map geo-referenced to real-world coordinates. Thirdly, compiling data on the geographic locations of hundreds of towns and villages to make the maps searchable. And, fourthly, developing the web platform itself.

We see the present version of the POM platform only as a starting point. Our intention is to fully digitize the information contained within the maps, and to geographically catalogue many other open resources that already exist online, including historic photographs and oral histories. We also intend to make our source code for the platform freely available to others who would like to start similar projects in other parts of the world.

\section{Past as Present, the Sustained Power of Maps}

They show a map, with dots. Dots, dots, dots ... Dots, from the north of the country to the south, south of Beersheva. And these dots, which are the villages they're referring to, these dots are located everywhere in the state of Israel ... Here, in Tel Aviv. I found them in the Tel Aviv area, dozens of dots. In Bat Yam, in Rishon LeZion, in Rehovot - they're everywere [sic].

Limor Livnat, an Israeli minister, speaking in the Knesset on 5 February 2012 (translated by Kamen 2012). 
In the above excerpt from a debate in the Israeli Knesset, Livnat is describing her experience of iNakba, a smartphone app produced by Zochrot, an Israeli NGO working to educate Jewish Israelis about the Palestinian Nakba and advocating for the right of Palestinian refugees to return. The "dots" she describes are markers locating the $500+$ destroyed Palestinian villages that are scattered across present-day Israel. Her reaction to the app-which goes on to sway between implying that the maps are false and declaring that discussion of Palestinian return should be outside of "the political argument"-mirrors a wider Israeli discourse described by Zochrot co-founder Eitan Bronstein (2009) in which the Nakba is "something that did not occur (although it had to occur)".

Whereas in the past cartography was the exclusive preserve of those who commanded the necessary power and resources, today anyone with access to a computer and the internet has the tools at their disposal to challenge official historical records and cartographies by mapping their own narrative. It is no longer possible to maintain Moshe Dayan's implied "ignorance" defence for historical denial that "these geography books no longer exist" when their contents become omnipresent online. With overwhelming historical evidence in the public domain, the limits of "the political argument" must surely eventually shift. 


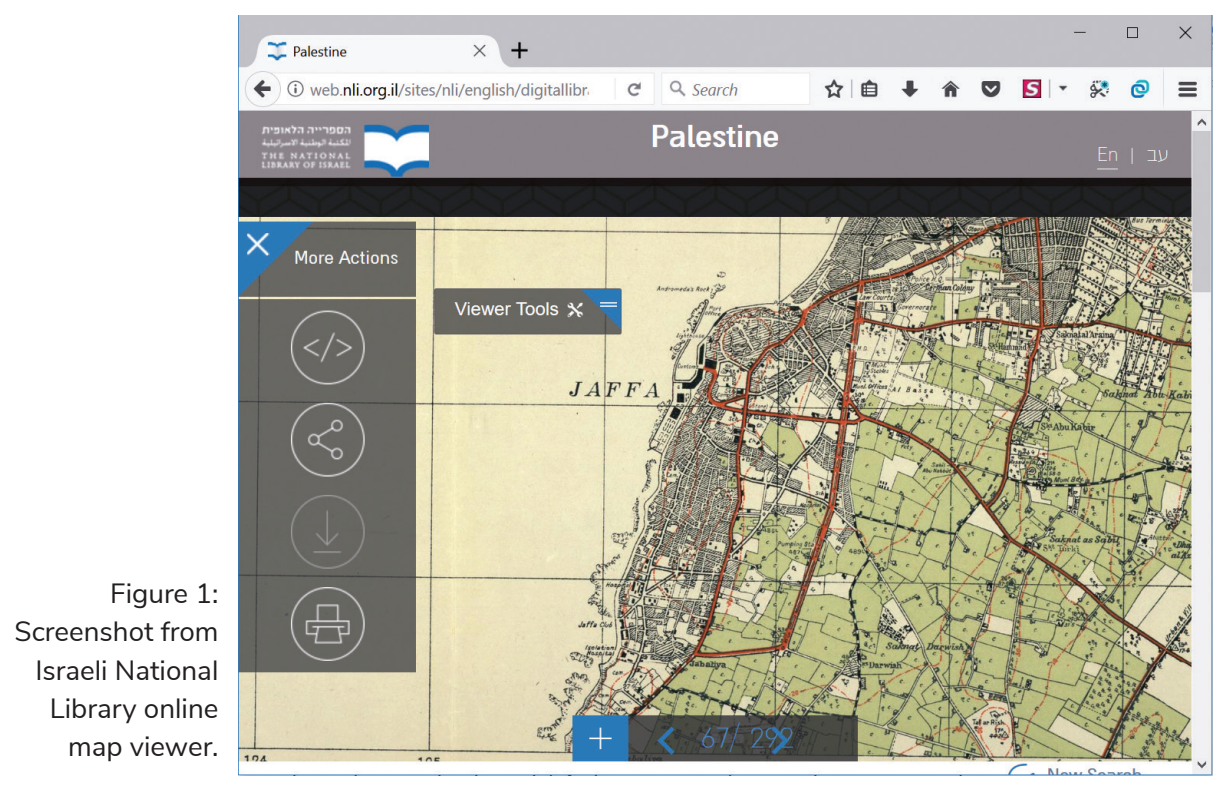

Figure 2: 1:250,000 Palestine (1946), north sheet ( 1 of 3 sheets).

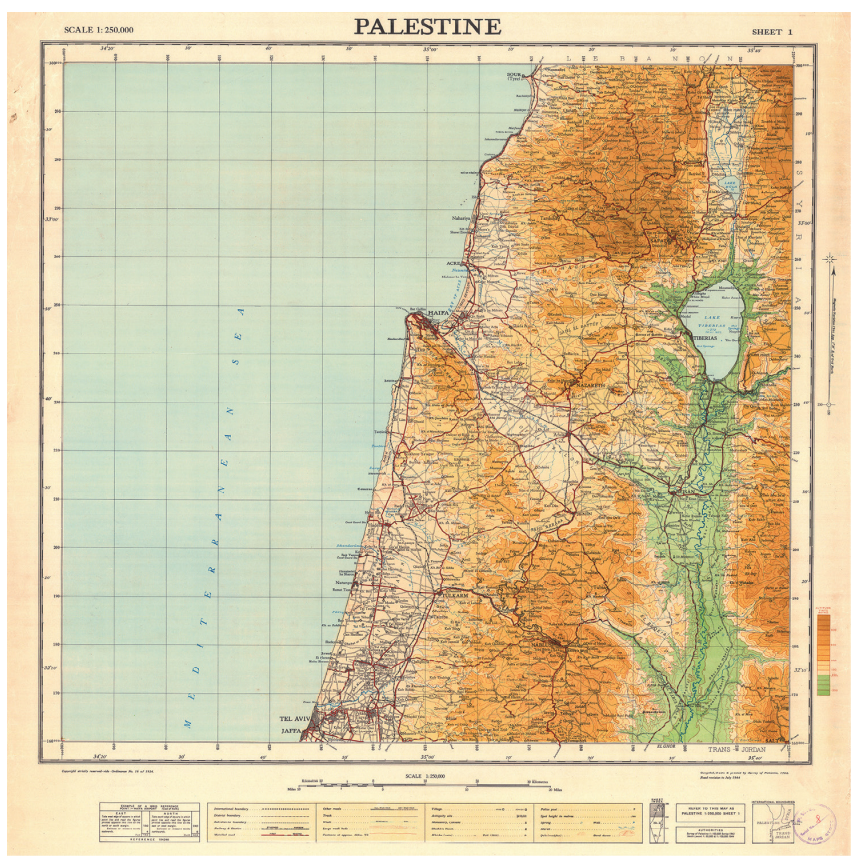



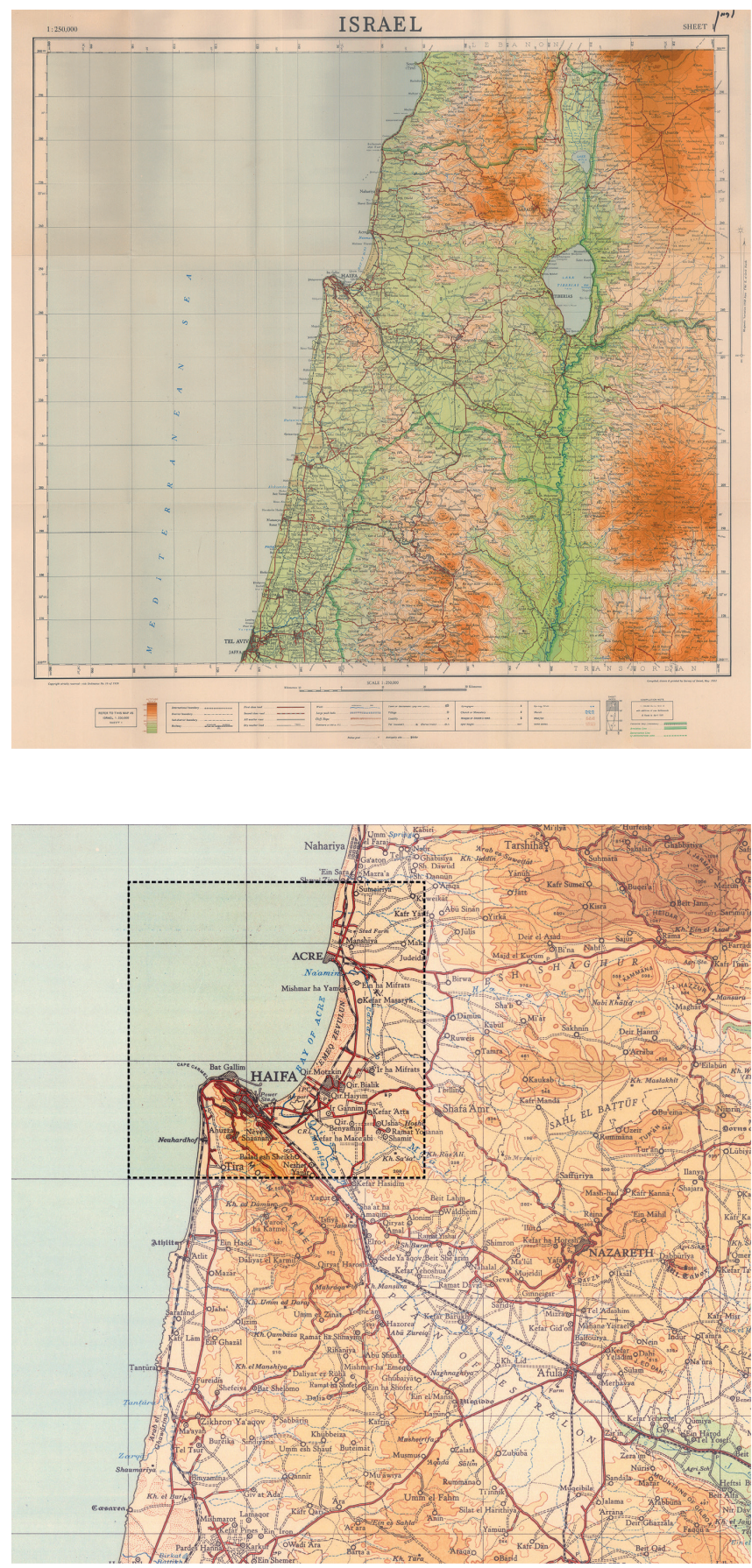

Figure 3:

1:250,000 Israel (1951), north sheet (1 of 3 sheets).
Figure 4:

Detail from 1:250,000

Palestine (1946), north sheet (1 of 3 sheets). 
Figure 5: Detail from 1:100,000 Palestine (1942), Haifa (1 of 16 sheets).
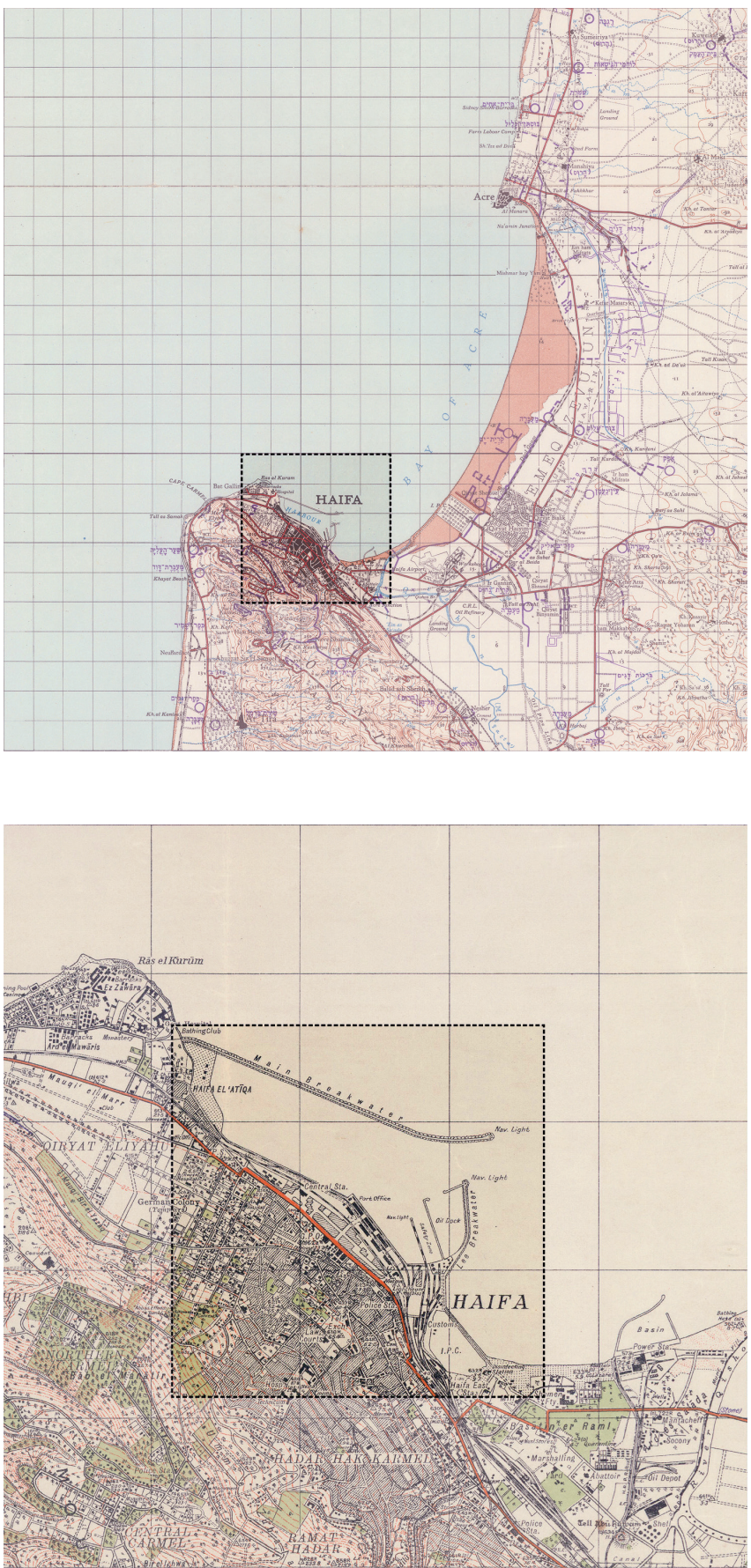

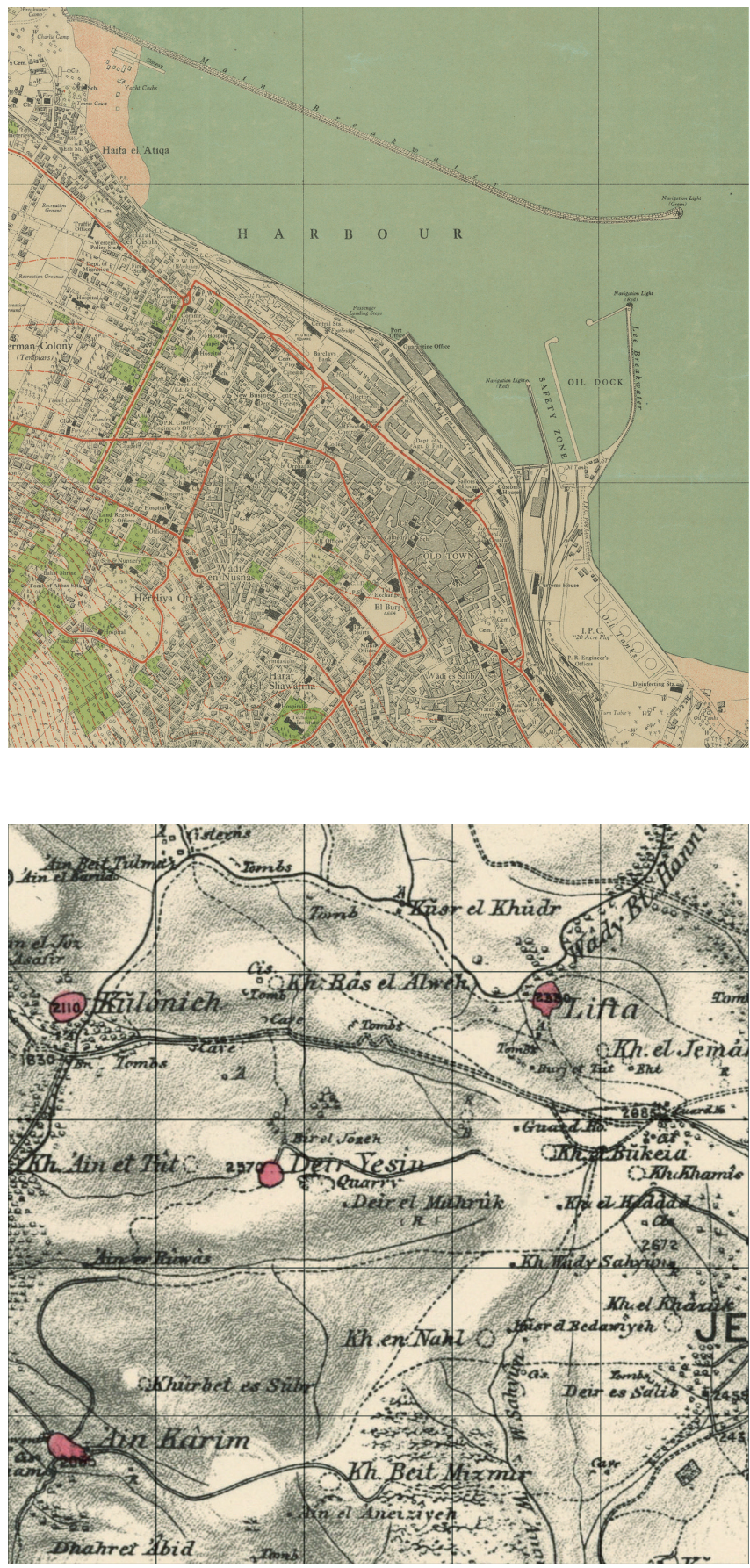

Figure 7: Detail from 1:10,000 Haifa (1943), Sheet 1 (of 4).
Figure 8: Detail from Palestine Exploration Map (1880) showing region west of Jerusalem. 
Figure 9: Detail from

Palestine 1:20,000 (1942) showing region west of Jerusalem.

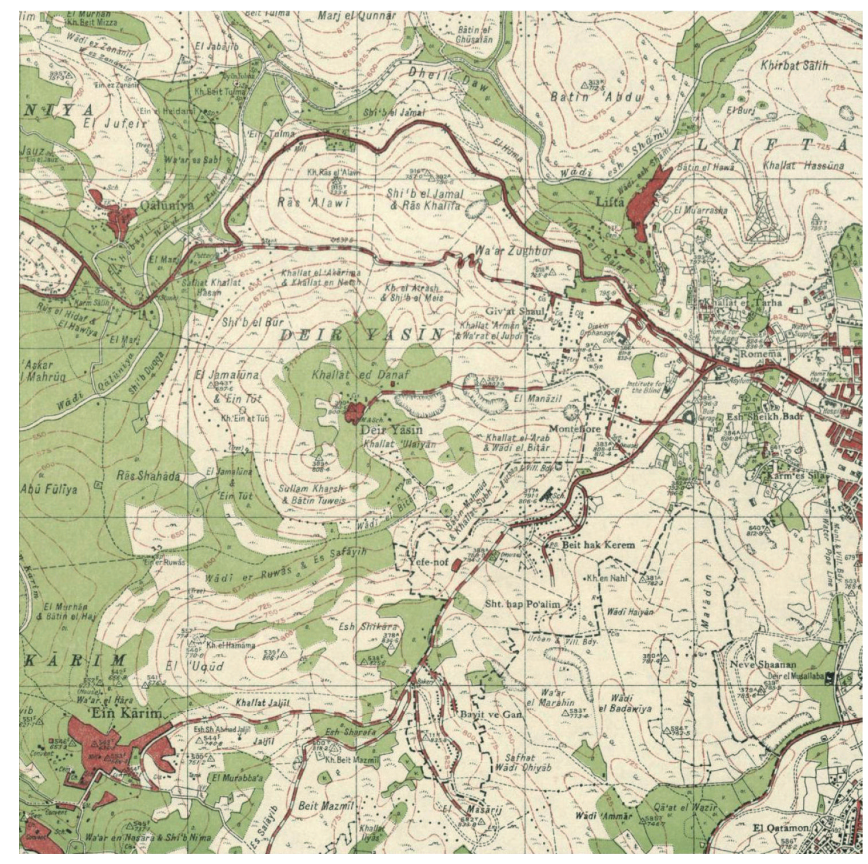

Figure 10: Aerial photography (Mapbox/ OpenStreetMap 2019) showing region west of Jerusalem.

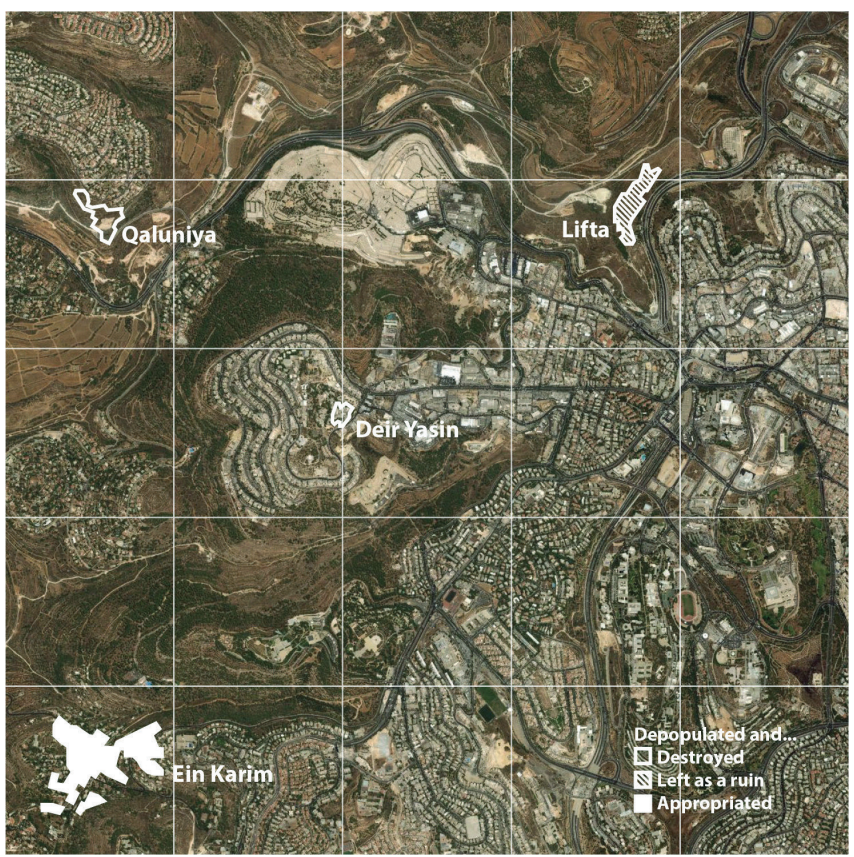


AHMAD BARCLAY is a a rchitect, visual communicator, and product designer with Visualizing Impact. He can be reached at arkbarclay@ cantab.net.

\section{References}

Abu Sitta, Salman. 2010. Atlas of Palestine, 1917-1966. London: Palestine Land Society.

Benvenisti, Meron. 2000. Sacred Landscape: The Buried History of the Holy Land Since 1948. Berkeley, CA: University of California Press.

Bronstein, Eitan. 2009. "The Nakba: Something That Did Not Occur (Although It Had to Occur)" Zochrot, August. https://www. zochrot.org/en/article/50644.

Gavish, Dov. 2005. A Survey of Palestine under the British Mandate, 1920-1948. Abingdon: RoutledgeCurzon.

Kamen, Charles. 2012. “Tel Aviv Police Blockade Zochrot's Offices to Prevent a Legitimate Protest". Zochrot, April. https://www. zochrot.org/en/article/53637.

Pappe, Ilan. 2006. The Ethnic Cleansing of Palestine. Oxford: One World.

Rapoport, Meron. 2007. “History Erased”. Ha'aretz, 5 July. https:// www.haaretz.com/1.4950011. 